\title{
Patterns of Discomfort
}

\author{
Conne Bazley ${ }^{1^{*}}$, Rachel Nugent ${ }^{2}$ and Peter Vink ${ }^{1}$ \\ ${ }^{1}$ Faculty of Industrial Design Engineering, Delft University of Technology, Landbergstraat 15, 2628CE Delft, the Netherlands \\ ${ }^{2}$ National University of Ireland, Galway (NUI Galway), University Road Galway, Ireland
}

*Corresponding author: Conne Bazley, Faculty of Industrial Design Engineering, Delft University of Technology, Landbergstraat 15, 2628CE Delft, the Netherlands, Tel: +1(310)394-1811; Email: cbazley@jimconna.com

Rec date: Dec 19, 2014; Acc date: Feb 15, 2015; Pub date: Feb 22, 2015

Copyright: (c) 2015 Bazley, et al. This is an open-access article distributed under the terms of the Creative Commons Attribution License, which permits unrestricted use, distribution, and reproduction in any medium, provided the original author and source are credited.

\begin{abstract}
A review of literature on comfort and discomfort indicates an increase in physical discomfort during the workday. In this paper, three different types of occupations were studied to identify whether a similar discomfort pattern exists in these occupations while participants perform work throughout the work day and workweek. Results are that sedentary and labor intensive occupations show an increase in physical discomfort throughout the workday. In addition, during the workweek, each occupation had a peak discomfort day and all occupations experienced a reduction of discomfort at the end of the last day of the workweek. Acknowledging and understanding why, when, and where discomfort peaks occur could assist in varying task scheduling to improve job performance. Future research should include emotional and psychological discomfort assessments, investigation of effects of age, time of year, and location in the world are warranted.
\end{abstract}

Keywords: Patterns; Discomfort; Comfort; MSD; Workweek; Task; Performance

\section{Introduction}

The term Musculoskeletal Disorder (MSD) applies to a broad range of disorders and injuries (e.g. sprain, strain) of the musculoskeletal system. These occur when the demands of an activity exceed the capacity or limitations of the musculoskeletal components [1]. Symptoms of MSDs include numbness, tingling, aches, pain, localized inflammation, weakness, and/or difficulty in moving joints, which can significantly reduce the ability to do work or carry out daily activities [2]. MSDs can occur suddenly due to a single incident e.g. handling a heavy load [1] or due to a sudden movement (slip/trip/fall) [3]. Alternatively, they develop gradually over long periods and are frequently referred to as Cumulative Trauma Disorders (CTDs) [4] or Repetitive Strain Injury (RSI) e.g. tendonitis, bursitis and carpal tunnel syndrome [5]. As the disorder progresses, individuals experience symptoms on a more frequent basis [5]. Symptom severity increases in intensity, becomes chronic and symptoms are experienced for longer durations. In severe cases, symptoms are experienced constantly and the individual becomes permanently disabled [5].

The brain interprets situations where physiological limitations have been exceeded, perceiving varying intensities of sensations that correspond with the magnitude in which limits have been exceeded. These sensations signal that internal homeostasis is disrupted and recovery steps are required. Physical sensations include mild to severe aches, pains and discomfort, and perceived sensations of fatigue and tiredness [6-9].

Many studies use discomfort recordings to check the effect of an intervention [10-12]. For instance, Groenesteijn et al. [11] used questionnaires on local postural discomfort to determine the difference in experience between two chairs. Reducing discomfort is not a luxury. Helander and Zhang [13] showed that discomfort is related to feelings of pain, numbness, and tiredness. Hamberg et al.
[14] showed that discomfort is a predictor of complaints in the back and neck and should be reduced for that reason. Discomfort is also related to human productivity. In order to stay ahead of business competitors, reducing employee discomfort during work hours is beneficial [15].

\begin{tabular}{|l|l|}
\hline Topics related to discomfort (n=318) & Percentage \\
\hline Patient discomfort (e.g. Music in treatment, give injections) & $52.5 \%$ \\
\hline $\begin{array}{l}\text { Behavior and discomfort (e.g. Discomfort intolerance and } \\
\text { behavior problems) }\end{array}$ & $7.9 \%$ \\
\hline Visual discomfort (e.g. Glare) & $6.6 \%$ \\
\hline Work organization and workplace (e.g. Effects of rest breaks) & $4.7 \%$ \\
\hline Musculoskeletal (e.g. Joint motion, seat/wheel chair) & $4.7 \%$ \\
\hline Eye discomfort (e.g. Effect of lenses) & $3.5 \%$ \\
\hline Thermal (e.g. Effect of ventilation) & $3.1 \%$ \\
\hline Driver discomfort (e.g. Noise) & $2.8 \%$ \\
\hline Vibration (e.g. Lateral vibration in trains) & $1.9 \%$ \\
\hline Hand tool/grip (e.g. Effects of handle design) & $1.9 \%$ \\
\hline Animal discomfort (e.g. Types of stables) & $1.9 \%$ \\
\hline Others (<1\% per topic) & $9.1 \%$ \\
\hline
\end{tabular}

Table 1: Topics studied in 318 papers between 2003 and 2013 with discomfort in the title.

Hewitt Associates [16] states, "Companies with higher growth in profitability have engagement levels that are more than $20 \%$ higher than those of their counterparts and provide more growth and development opportunities." However, discomfort research is not only related to musculoskeletal problems and productivity. A previous 
literature study of the MEDLINE database showed that between April 1993 and April 2003, 109 papers list discomfort in the title [15]. Discomfort is a main topic of study and most of the 109 papers concern patient pain studies (43 out of 109) and aspects of physical discomfort (35 out of 109). Thirty five studies discuss the effects of posture or assembly tasks on musculoskeletal discomfort and pressure during seating. A Science Direct review of discomfort related literature resulted in 318 papers submitted between 2003 and July 31st, 2013. The majority of studies over the past 10 years $(52.2 \%)$ are patient pain studies as displayed in Table 1. By combining the categories of musculoskeletal, driver discomfort, vibration, and hand tool, $11.3 \%$ of the papers are in the physical category. Emotional and psychological issues were not often mentioned in the titles. Helander and Zhang [13] distinguished the difference between comfort and discomfort in their article, Field studies of comfort and discomfort in sitting. Based on questionnaires by Zhang et al. [17] and Helander and Zhang, [13], discomfort was found to be related to physical characteristics of the environment, such as posture, stiffness, and fatigue. When discomfort is absent, nothing is experienced. Because comfort is related to luxury, relaxation, or feeling refreshed, more of these aspects need to be experienced in order to notice comfort. This division is affirmed by the fact that the comfort scales did not appear to be useful for high physical load ( $>65 \%$ MVC) [18].

Publications are emerging on the importance of including emotional and psychological aspects of comfort in the area of environmental design [19]. Most of these studies do not mention the specific time of day the data was collected. However, Bosch et al. [10] showed that discomfort increases during a day of assembly work. In theory, a difference in discomfort found in several of the 318 studies (e.g. $[11,12])$ may be attributed to the way the measurement of discomfort was performed. For instance, the possibility is that a "new situation" recorded in the morning is the "old situation" recorded in the afternoon. Perhaps during the week, patterns are found that have the same effects and disturb discomfort findings. The purpose of this study is to identify if discomfort patterns are present during the workday and throughout the workweek. If a pattern exists across all work occupations it may be useful information for future discomfort experiments to gain theoretical knowledge on how and when these patterns evolve and occur during the workday and workweek. Additionally, knowledge of discomfort patterns and peaks may assist in job design of work tasks and task scheduling to off-set days lost due to health issues for employees thereby creating a more productive, cost saving work environment $[15,16]$.

This research attempts to address whether there is a common pattern in the physical discomfort experience for different working professions during the work day and work week. The scope of this research encompasses evaluation of three studies related to discomfort in three occupational settings. The majority of workplace studies are in offices and most often include sedentary work. Therefore, this study includes two sedentary occupations which differ in content: an administrative job and a knowledge intensive job. The third occupation is a physical demanding job and chosen to show possible differences or similarities to the sedentary occupations regarding a pattern in discomfort.

In each of the three studies, discomfort was recorded three or four times throughout the day as well as throughout a work week. A different method for recording discomfort was used for each study. The emotional and psychological discomfort levels were recorded in only one of these studies. The purpose of this study is to examine whether there is a common pattern of physical discomfort despite the different collection methods used in three different countries, and three different occupations.

\section{Methods}

\section{Participants}

Three professions were selected to compare patterns of discomfort for this study: engineering professionals located in the USA [20]; administrative personnel located in the Netherlands [21]; and physical plasterers located in Ireland [22]. All three studies were performed in the spring of the year. Consent was granted by the three authors [20-22] to compare the results of their studies. Authors from each study obtained permission from all participants through the use of signed consent forms.

\section{Materials and Procedures}

\section{Engineering professionals}

A four-day self-assessment survey on comfort was administered to sixteen engineering professionals performing desk work consisting of control-system engineering activities designing, and developing, electrical, and instrumentation systems. The work involved intensive decision-making and problem solving, interacting with mainframe computers specialized software programs and developing constructive relationships with department chiefs, business unit leaders, contractors, and external vendors. Eleven males and five females were surveyed and the age of the participants ranged between the ages of 22-60. The survey encompassed one workweek. A typical work week began on Monday and ended Thursday. Each work day was ten to eleven hours long. The participants received a package of four surveys to begin the survey the following day.

The method used to measure participant responses to physical, psychological and emotional comfort assessment or symptom severity throughout the day was based on a Likert rating scale. Numbers were assigned to a person's estimation of his/her symptoms and were meaningful. It allowed for a standardization of a variable, 'symptom severity', which can be highly subjective. This created uniform levels that were effectively used for statistical analysis. For this type of study, Likert responses were easier to administer and interpret and were a preferable method of measurement $[23,24]$.

The first set of survey questions for a Likert scale rating,1-5 (1, excellent to 5, very bad), asked about physical, psychological, and emotional comfort in the morning upon waking. In addition, participants were asked to circle a word best describing the level of comfort. The next set of questions asked for information about comfort levels after arriving at work (physical, psychological and emotional, each level rated 1-5).

The last part of the survey was completed at the end of workday and participants were asked to rate their comfort level (physical, psychological, and emotional, each rated 1-5). In addition, participants were to circle a word that best described what made them most comfortable and most uncomfortable in the office setting. A one sided Wilcoxon signed rank, using SPSS Statistics for Windows, Version 20.0, was applied for the difference between the beginning and the end of the workday. It is hypothesized, based on the work of Bosch et al. [10], that discomfort is higher at the end of the day and physical 
comfort is lowest at the end of the day $(\mathrm{p}<0.05)$. A polynomial regression line was calculated for the pattern in discomfort during the week to describe the pattern. For the difference between the pre-work (to compare with the other two studies possible) and the highest point in the curve in the week, a one side Wilcoxon signed rank test was also applied $(\mathrm{p}<0.05)$.

\section{Administrative personnel}

Ten participants (six male and four female) were studied performing desk work which included, arranging meetings by phone and email, making layout or reports, making letters, answering phone and emails for the staff, preparing forms, for 8 hours a day. The age of the participants ranged between ages 20-60. Local Postural Discomfort (LPD) recordings were made during a five-day workweek: each day for two weeks; half an hour after starting work, half an hour before lunch, and half an hour before end of workday. The LPD method was used and consisted of a map with twelve body regions [23].

A ten point-Borg scale was used to assess discomfort (ranging from 'No Discomfort' at 0 and 'Extreme Discomfort' at 10) per region [24]. At the end of each day, a general questionnaire of what made people feel both comfortable and uncomfortable was completed. The average pattern of LPD during the day was recorded for two weeks. As in the previous study, the beginning and end of the workday were tested with Wilcoxon, a polynomial regression line was calculated, and the peak in the week line was tested against the beginning of the week value.

\section{Physical plasterers}

Eighteen male plasterers (physical laborers) were surveyed as they carried out their usual physical activities of applying coats of plaster to interior walls, ceilings, and partitions of buildings, to produce finished surface, according to blueprints, architect's drawings, or oral instructions, using hand tools and portable power tools and mixing plaster and erecting scaffolds, during their work week. Participants declined to complete the demographic portion of the survey.

A Body Part Discomfort Survey (BPDS) was used in the study. It consisted of a body map sectioned by color and labeled to indicate ten body parts of interest, ten questionnaires, and twenty batches of ten Visual Analogue Discomfort Scales (VADS), one batch for each time event [25-27]. The body parts of interest in this study were the neck, upper back, shoulders, mid back, elbows, low back, wrists/hands, buttocks/hips/thighs, knees, and ankles/feet. Individual VADS represented a single body part for each time event. The 100 millimeters $(\mathrm{mm})$-vertical lines were labeled 'No Discomfort' at $0 \mathrm{~mm}$ and 'Extreme Discomfort' at $100 \mathrm{~mm}$. At each corresponding time event, plasterers marked a point along a VADS line to indicate their level of perceived discomfort for each corresponding body part. Twice a day, plasterers completed a questionnaire to indicate the activities they carried out in the previous work session and to detail their work times and break times. The participants were required to indicate the intensity level of their perceived discomfort in ten body parts at twenty different time events: four times a day (BW-before work, BL-before lunch, AL- after lunch, EW-end of work) for five consecutive workdays.

The average discomfort intensity for the ten body parts was calculated for each time event. Comparative analysis was carried out between the average discomfort intensity for all ten body parts and days of the week, and between average discomfort and the twenty time events. As in the previous studies, the beginning and end of the workday were tested with a one sided Wilcoxon signed rank, using SPSS Statistics for Windows, Version 20.0. The data presented in the figures represents the average discomfort value for all subjects. A polynomial regression line was calculated to describe the patterns and the peak values at the end of the week was tested against the value at the beginning of the week. Standard deviation is not shown in the figures of this study because the figures show the sum of all subjects, which is only one value.

\section{Results}

\section{Engineering professionals}

The physical discomfort was low at waking and increased during the workday averaged over the four days (Figure 1). Psychological discomfort was higher at waking, lower on arrival to work and increased by the end of the workday. Emotional discomfort was higher at waking and decreased towards the end of the workday. There were no significant effects on physical or emotional levels for a two-way repeated measures ANOVA test with DAYS and Time of Day (TOD) as factors. A marginally significant $\mathrm{F}:(\mathrm{p}=0.051)$ DAYXTOD interaction was observed for the psychological comfort level suggesting that levels improved slightly. The results of the Wilcoxon test indicated that the difference between the beginning and end of the workday for physical discomfort was not significant for all types of comfort.

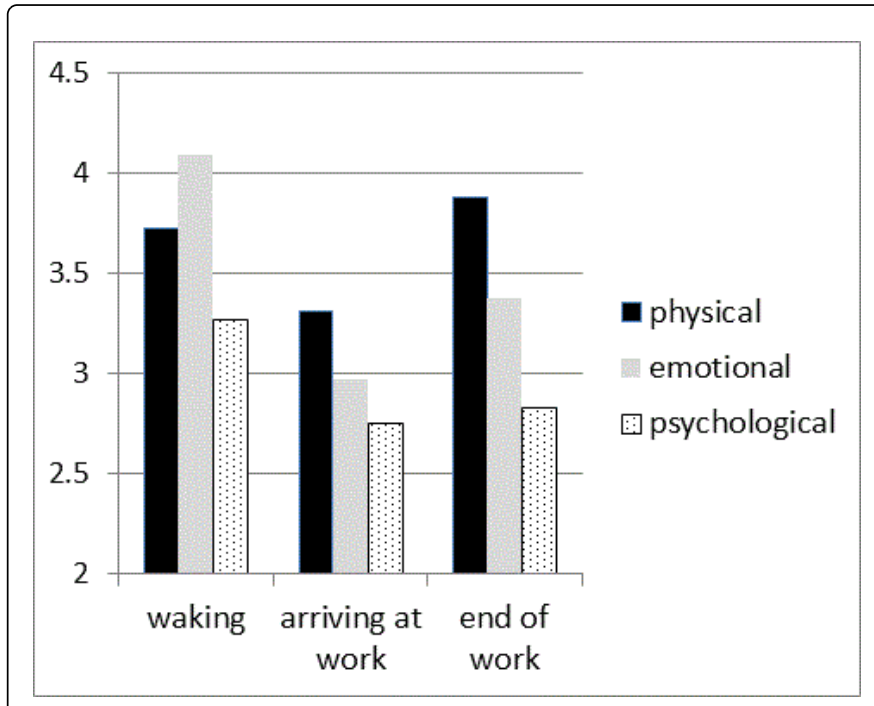

Figure 1: Physical, psychological and emotional comfort Level over work week averaged over all Engineering Professionals $(n=16)$ (rating 1-5; one, being excellent - five, being very bad). The solid columns indicate the corresponding values for Physical Comfort during the day, dotted columns correspond to Psychological Comfort and gray columns correspond to Emotional comfort [20].

Regarding the engineering professionals workweek study, the pattern that correlates highest was a fourth degree polynomial regression $\left(R^{2}\right.$ physical $=0.4386, R^{2}$ emotional $=0.7586$, and $R^{2}$ psychological $=0.6057$ (Figure 2). The peak physical discomfort at the end of Monday was significantly different from the pre-work value $(\mathrm{p}=0.054, \mathrm{t}=1.704)$. 


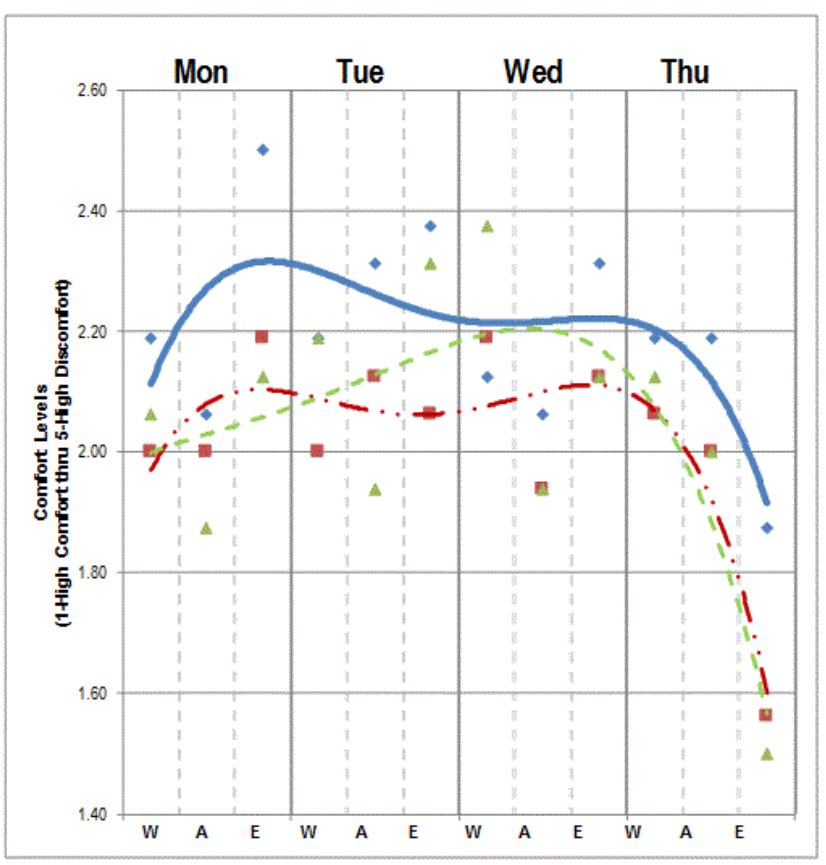

Figure 2: Comfort Level Trend lines over Workweek based on a four-day workweek of all Engineering Professionals $(n=16)$. WWaking, A - Arrive at Work and E=End of Work. The solid (-) line indicate the corresponding values Correlation Coefficient $\left(\mathrm{R}^{2}\right)$ for Pattern lines Regression Analysis using 4th Degree Polynomial for Physical. The dashed line (- -) corresponds to Psychological and the dash dot (- .-) line corresponds to Emotional [20].

\section{Administrative personnel}

The physical discomfort was low at the beginning of the workday and increased during the workday as averaged over the ten-day period (Figure 3). The end of the workday discomfort was significantly different from the discomfort after half an hour of work ( $\mathrm{p}=0$; Zvalue $=-6.8715)$. In the workweek study, the pattern that correlates highest was a fourth-degree polynomial regression line $\left(\mathrm{R}^{2}=0.39\right)$ (Figure 4). The peak was shown to occur on Wednesday and was significantly different from data received on Monday $(p=0.00391 ; \mathrm{Z}$ value $=-2.6552$ ).

\section{Physical plasterers}

Overall, the pattern for perceived discomfort intensity increased over a workday and throughout the workweek. A decline in intensity levels was observed after a period of rest (i.e. lunch and overnight) with the greatest decline occurring after an overnight break (Figure 5).

The workweek pattern that correlates highest was a $4^{\text {th }}$ degree polynomial regression line $\left(\mathrm{R}^{2}=0.88\right)$ (Figure 6). The difference between the beginning and end of day is significant $(\mathrm{p}=0 ; \mathrm{Z}$ value $=-6.154)$ and the difference between the peak on Thursday is significant from the beginning of the workweek ( $\mathrm{p}=0.00226$; Zvalue $=-2.8362$ ).

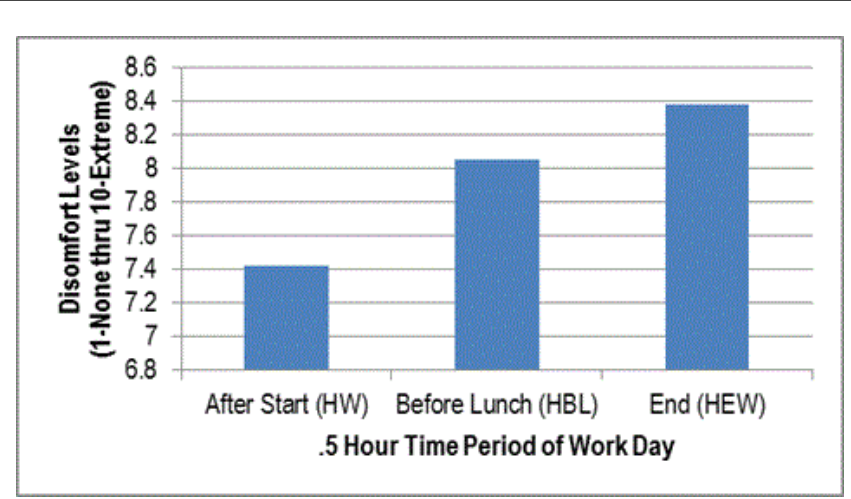

Figure 3: The Local Postural Discomfort summed over all admin participants $(n=10)$ over 10 Days at beginning halfway and end of the day (rating 0-10; 0 no discomfort to 10 extreme discomforts). Half an hour (HW) after the start of work; half an hour before lunch (HBL), and -half an hour before end of the workday (HEW) [21].

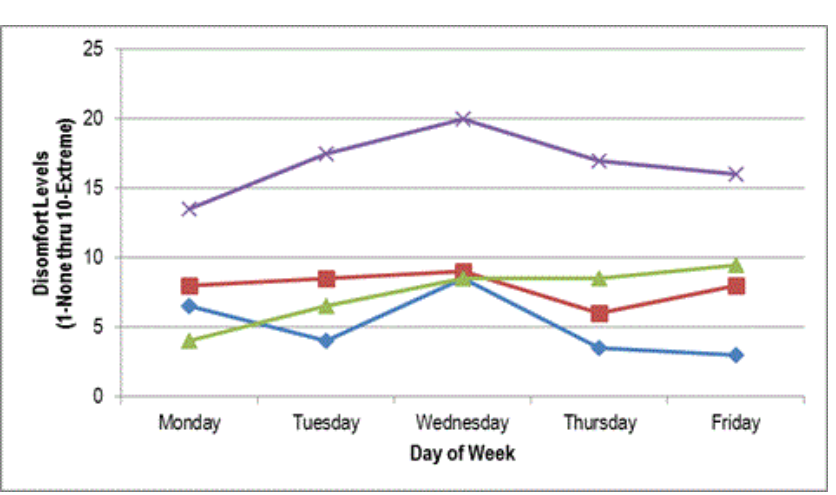

Figure 4: Sum of all Local Postural Discomfort score of all administrative personnel $(\mathrm{n}=10)$ divided over the week (rating 0-10; 0 no discomfort to 10 extreme discomfort). From left to right symbols denote the following: Before Work $(\downarrow)$, Before Lunch $(\bullet)$, After Lunch ( $\boldsymbol{\Delta})$ and End of Work (X) [21].

\section{Discussion}

The results confirm time of day relationships for the administrative personnel workers and for the physical plasterers. Two of the three studies, the administrative personnel workers and physical plasterers show an increase in physical discomfort during the day. The increase during the day is in line with the findings of Bosch et al. [10]. Feeling tired and having lower comfort levels at the end of a workday is consistent with findings by Vink et al. [21]. However, the engineering professionals study shows no significant increase for physical discomfort during the day although there was a marginal significance for the psychological discomfort level during the day. 
Page 5 of 7

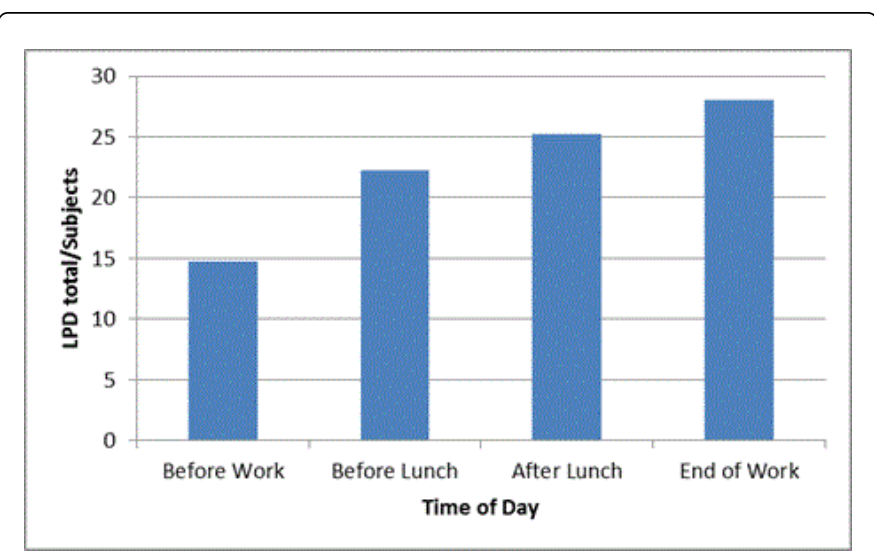

Figure 5: Local Postural Discomfort summed up over all body regions and averaged over physical plasterers $(n=18)$ and 5 days at four times during the day as recorded on $100 \mathrm{~mm}$ VADS scales $(0-$ 'No Discomfort', 100- -'Extreme Discomfort'). Before work (BW), before lunch $(\mathrm{BL})$, after lunch $(\mathrm{AL})$, and EW-end of work $(\mathrm{EW})$. LPD=Local Postural Discomfort (LPD) by Subjects for a 5 day period [22].

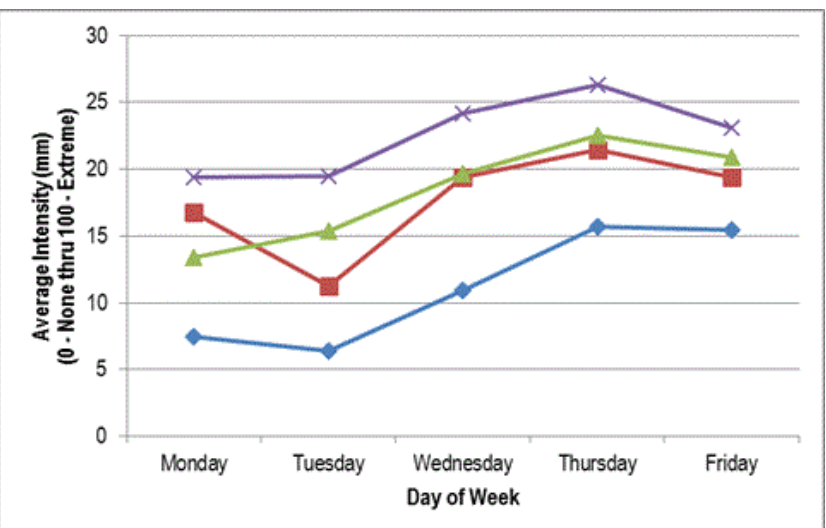

Figure 6: Local Postural Discomfort summed up over all body regions and averaged over physical plasterers $(\mathrm{n}=18)$ and at the end of different days in the week as recorded on $100 \mathrm{~mm}$ VADS scales (0-'No Discomfort', 100--'Extreme Discomfort'). From left to right symbols denote the following: Before Work $(\bullet)$, Before Lunch $(\bullet)$, After Lunch ( $\mathbf{\Delta})$ and End of Work (X) [22].

Murata et al. [28] state that anticipation about cognitive work being completed can cause a decline in comfort due to anxiety and the nature of cerebral work. The intensity threshold for physical discomfort was lower than that of the psychological discomfort and it is possible that the job tasks were intense enough to override the physical discomfort as described by Vink [15]. The study for the engineering professionals was over four days as opposed to the administrative personnel office study spanned over two weeks of five days for each week. It is possible that after being asked to assess discomfort for a longer period of time, that the administrative personnel had a greater awareness of discomfort. Additionally, similarities and differences in chair and workstation design, office layout, were not compared in the two sedentary studies and the differences may attribute to the absence of physical discomfort in the engineering study and the presence of physical discomfort at the end of the work day.

All three studies showed a peak discomfort at the latter part of the week which was significantly different from the beginning of the week. For the overall workweek, all three studies indicated a low physical discomfort at the beginning of the workweek, a rise in discomfort midweek, and by the end of the week, the physical discomfort was low again. The peak of discomfort occurred on different days for all three occupations. The peak for the engineering professionals was observed at end of the first workday, Monday. The difference between relaxed activities on the weekend and returning to sedentary intensive knowledge work related activities was significant enough that physical discomfort was noticed the end of the first day of the workweek. The administrative personnel noticed the peak of discomfort on Wednesday. The Wednesday peak may have occurred because the beginning of the week is often very busy. There may be no time to register the discomfort until midweek when there is a break in the routine. Another explanation is similar to that of the engineering professionals that participants are away the work activities on the weekends and for the administrative personnel it took several days after returning to the work activities to register the discomfort. Ryan et al. [31] found that much of the weekend effect would be accounted for by the work versus non-work contrast, given that work activities are expected to be associated with a lower sense of autonomy and relatedness than non-work activities.

In the physical plasterers study, it is possible that discomfort levels peaked on Thursday, rather than the last day of work (Friday) because of the type of physical activities performed. Plasterer working environments and task demands vary on a daily basis. Generally, the initial activities in the earlier part of the week or the finishing activities on-site usually require more preparatory work can be more physically demanding. These activities include plastering ceilings and upper/ lower wall surfaces. Work activities may be less physically demanding later in the week in preparation for the weekend, or when the job nears completion.

All three studies showed a lowering in physical discomfort level by the end of the day for the last day of the work week. This is consistent with studies by Sonnentag S et al. [29] in which participants are ready for the weekend and exhibit excitement and positive expectations for upcoming days off, or the weekend. Although the plasterers were asked to complete additional questions on comfort, they declined. However, additional comfort questions were asked in the other two studies. The engineers and administrative participants were asked to indicate what made them most comfortable and uncomfortable in the office. Participants in both of the office studies found that "people" made them most comfortable, however "people" also made them most uncomfortable. The mood and responsibilities for each day was also influenced by "people" making employees feel more or less comfortable during the workweek in conjunctions with variations in personal duties, interactions, and biorhythms.

Participants in both of the office studies also found that "task" made them most comfortable. According to Kaye [30], exciting and challenging work, opportunities for career growth, learning and development, high-quality co-workers, fair pay, and supportive management are the six top reasons employees stay with a particular company. Herzberg et al. [31] describes that motivators create satisfaction by fulfilling individuals' needs for meaning and personal growth. The issues such as the work or "task" itself and advancement 
are related to satisfaction. These studies align with the finding in this study that finishing the task is an important factor for comfort at work.

An important component of physical discomfort for the office studies was office temperature and inner climate. Participants indicated that "temperature" and "inner climate" made then most uncomfortable. The relationship between discomfort and "temperature" is found in other studies (e.g. [32,33]). The natural environment affects not only the physical health but also the psychological health of human beings [34]. The engineering office had forced air conditioning and was not well regulated throughout the building. Additionally, the windows did not open and the engineers had no control over the temperature. On the other hand, the administrative personnel office subjects were able to open windows and somewhat regulate temperature There are many studies in environmental psychology research related to the effect of natural elements in the "inner climate". For example, window size, sunlight penetration and the presence of plants influences workers' moods [34]. Bakker and Voordt [35] and Stokols [36] state that, "physical, emotional and social conditions together are a requisite for good health."

\section{Limitations}

Ideally, a case study analysis should have multiples of cases included. However, it is not common to find numerous field studies researching discomfort throughout the day and throughout the week for different occupations in different countries. For this study three different occupations in different countries, using different comfort questionnaires found an increase in physical discomfort throughout the work day and work week. The data collected were only from natural settings. This meant that selection effects were possible regarding gender, age, nationality, and time of year as well as type of occupation (two sedentary, one physical labor). Males and females participated in the two sedentary studies. However, there were only male participants in the physical labor study. There are varying discomfort and comfort tolerances for different age groups and genders. These variations provide difficulty for determining degrees of discomfort levels. Although quantitative results can be reported, many variables exist in real life studies and generally require qualitative reported results. Non-laboratory work study results often conflict with laboratory models [37,38]. According to studies by Vink [15], physical conditions are an important comfort factor. The discomfort pyramid of Bubb [39] demonstrates that if the environment is unpleasant the physical conditions will ultimately overrule all other factors if not addressed $[39,40]$. However, the emotional and psychological connections, although defined by Höppe [41] as, "difficult to deal with" may be more important for the sustainability of comfort $[19,42]$.

\section{Conclusion}

The purpose of this study is to identify whether discomfort patterns are present during the workday and throughout the workweek. Common physical discomfort patterns were found during the workday and throughout the workweek. One sedentary and the physical labor study work showed an increase in physical discomfort during the day. During the workweek, all three occupations had a peak discomfort day. All three studies showed a lower discomfort at the end of the of the workweek day. This sample size indicated a pattern across varied work occupations.
Future studies on how, when, and why these patterns evolve and occur during the workday and workweek should incorporate this comfort component in the experimental set up. Acknowledging and understanding why, when, and where discomfort peaks occur during the workweek could assist with changes in task scheduling and task performance particularly on days that are identified as peak discomfort days. Implementation of variation in work tasks in all occupations throughout the week and particularly on the identified peak discomfort day could possibly deter the on-set of MSDs, emotion and mental fatigue. Studies on discomfort and patterns of discomfort should consider the inclusion of many different occupations from around the world. The benefits of a holistic approach to discomfort should include emotional and psychological discomfort assessments and confirm whether effects e.g. age, gender, race, time of year, temperature, lighting, humidity, expectations, experience, and geographic location influence physical discomfort and peak discomfort days.

\section{References}

1. Hildebrandt VH (1995) Back pain in the working population: prevalence rates in Dutch trades and professions. Ergonomics 38:1283-1298.

2. Larson NLJ (2013) Corporate Ergonomics: It's Musculoskeletal Disorder Management and System Optimization. Ergonomics in Design 20:29-32.

3. Costa BR, ER da Vieira (2010) Risk factors for work-related musculoskeletal disorders: A systematic review of recent longitudinal studies. Am J Ind Med 53:285-323.

4. Staal JB, de Bie RA, Hendriks EJ (2007) Aetiology and management of work-related upper extremity disorders. Best Pract Res Clin Rheumatol 21:123-133.

5. IJmker S, Huysmans MA, Blatter BM, van der Beek AJ, van Mechelen W, et al. (2007) Should office workers spend fewer hours at their computer? A systematic review of the literature. Occup Environ Med 64:211-222.

6. Öztürk N, Esin MN (2011) Investigation of musculoskeletal symptoms and ergonomic risk factors among female sewing machine operators in Turkey. International Journal of Industrial Ergonomics 41:585-591.

7. da Costa BR, Vieira ER (2010) Risk factors for work-related musculoskeletal disorders: a systematic review of recent longitudinal studies. Am J Ind Med 53:285-323.

8. Boocock MG, Collier JM, McNair PJ, Simmonds M, Larmer PJ, et al. (2009) A framework for the classification and diagnosis of work-related upper extremity conditions: systematic review. Semin Arthritis Rheum 38:296-311.

9. Buckle PW, Devereux JJ (2002) The nature of work-related neck and upper limb musculoskeletal disorders. Appl Ergon 33:207-217.

10. Bosch T, de Looze MP, JH van Dieën (2007) Development of fatigue and discomfort in the upper trapezius muscle during light manual work. Ergonomics 50:161-177.

11. Groenesteijn L, Vink P, de Looze M, Krause F (2009) Effects of differences in office chair controls, seat and backrest angle design in relation to tasks. Appl Ergon 40:362-370.

12. Schoenmarklin RW, Marras WS (1989) Effects of Handle Angle and Work Orientation on Hammering: I Wrist Motion and Hammering Performance Human Factors. Hum Factors 31:397-411.

13. Helander MG, Zhang L (1997) Field studies of comfort and discomfort in sitting. Ergonomics 40:895-915.

14. Hamberg-van Reenen HH, van der Beek AJ, Blatter BM, van der Grinten MP, van Mechelen W, et al. (2008) Does musculoskeletal discomfort at work predict future musculoskeletal pain? Ergonomics 51:637-648.

15. Vink P (2005) Comfort and Design: Principles and Good Practice. CRC, London.

16. Hewitt Associates (2004) Research brief: Employee engagement higher at double-digit growth companies. 
17. Zhang L, Helander MG, Drury CG (1996) Identifying Factors of Comfort and Discomfort in Sitting. Human Factors: Hum Factors 38:377-389.

18. Kong YK, et al. (2012) Comparison of comfort, discomfort, and continuum ratings of force levels and hand regions during gripping exertions. Applied Ergonomics 43:283-289.

19. Ong BL (2013) Beyond Environmental Comfort: Taylor \& Francis.

20. Bazley C, Vink P, Jong AD (2012) The influence of expectations and preexperiences on comfort at work. Advances in Social and Organizational Factors, Taylor \& Francis.

21. Vink P, Konijn, IK, Jongejan B, Berger M(2009) Varying the Office Work Posture between Standing Half-Standing and Sitting Results in Less Discomfort in Ergonomics and Health Aspects of Work with Computers. Springer: Berlin Heidelberg:115-120.

22. Nugent R (2012) Ergonomic Analysis of Work Related Musculoskeletal Disorder Risk to Plasterers Working in Ireland. National University of Ireland, Galway (NUIG), Unpublished Doctoral Thesis.

23. van der Grinten MP (1992) Development of a practical method for measuring body part discomfort. In: Kumar S (eds), Advances in industrial ergonomics and safety, Taylor and Francis: London.

24. Borg G (1990) Psychophysical scaling with applications in physical work and the perception of exertion. Scand J Work Environ Health 16 Suppl 1:55-58.

25. Belling C (2010) Commentary: sharper instruments: on defending the humanities in undergraduate medical education. Acad Med 85:938-940.

26. Cameron JA (1996) Assessing work-related body-part discomfort: Current strategies and a behaviorally oriented assessment tool. International Journal of Industrial Ergonomics 18:389-398.

27. Huskisson E (1983) Visual Analogue Scales in Pain Measurement and Assessment. Raven Press: New York.

28. Murata A, Uetake A, Takasawa Y (2005) Evaluation of mental fatigue using feature parameter extracted from event-related potential. International Journal of Industrial Ergonomics 35:761-770.
29. Sonnentag S, Mozja EJ, Binnewies C, Scoll A (2008) Being engaged at work and detached at home: A week-level study on work engagement, psychological detachment and affect. Work \& Stress 22: 257-276.

30. Kaye B (2010) Love 'Em Or Lose 'Em: Getting Good People to Say. (4thedn), Berrett-Koehler Publishers, California.

31. Herzberg F (1959) The motivation to work. Wiley.

32. ANSI/ASHRAE, Standard-55-20004 (2004) Thermal environmental conditions for human occupancy. American Society of Heating, refrigerating and Air-Conditioning Engineers. ANSI/ASHRAE, Atlanta.

33. Valancius R, Andrius J (2013) Influence of indoor air temperature variation on office work performance. . Journal of Environmental Engineering and Landscape Management 21:19-25.

34. Sundstrom E1, Bell PA, Busby PL, Asmus C (1996) Environmental psychology 1989-1994. Annu Rev Psychol 47: 485-512.

35. Bakker I, van der Voordt $\mathrm{T}$ (2010) The influence of plants on productivity: A critical assessment of research findings and test methods. Facilities 28:416-439.

36. Stokols D (1992) Establishing and maintaining healthy environments. Toward a social ecology of health promotion. Am Psychol 47:6-22.

37. Heschong L (1979) Thermal Delight in Architecture. MIT Press, Cambridge.

38. Schiller GE, Arens EA, Bauman FS, Benton C, Fountain M, et al. (1988) A field study of thermal environments and comfort in office buildings. ASHRAE Transactions 94:280-308.

39. Bubb R (2008) Sitting comfort. IQPC aircraft interior innovation, Hamburg.

40. Vink P, Brauer K (2011) Aircraft Interior Comfort and Design. CRC Press, London.

41. Höppe P (2002) Different aspects of assessing indoor and outdoor thermal comfort. Energy and Buildings 34:661-665.

42. Green WS, Jordan PW (2003) Pleasure with Products: Beyond Usability. CRC Press, London. 